\title{
Optimizing electroporation assisted silver nanoparticle delivery into living C666 cells for surface-enhanced Raman spectroscopy
}

\author{
Yun $\mathrm{Yu}^{\mathrm{a}, *}$, Juqiang Lin ${ }^{\mathrm{a}, *}$, Yanan $\mathrm{Wu}^{\mathrm{b}}$, Shangyuan Feng ${ }^{\mathrm{a}}$, Yongzeng $\mathrm{Li}^{\mathrm{a}}$, Zufang Huang ${ }^{\mathrm{a}}$, \\ Rong Chen ${ }^{\mathrm{a}, * *}$ and Haishan Zeng ${ }^{\mathrm{c}}$ \\ ${ }^{a}$ Key Laboratory of OptoElectronic Science and Technology for Medicine, Ministry of Education, \\ Fujian Normal University, Fuzhou, Fujian, China \\ ${ }^{\mathrm{b}}$ Fujian Provincial Hospital, Fuzhou, Fujian, China \\ ${ }^{\mathrm{c}}$ Cancer Imaging Department, British Columbia Cancer Agency Research Centre, Vancouver, BC, \\ Canada
}

\begin{abstract}
Electroporation assisted metallic nanoparticle delivery has been shown by our previous work to significantly reduce the time of sample preparation for surface-enhanced Raman spectroscopy (SERS) measurements of biological cells. In this paper, we report our experimental work to optimize the electroporation parameters, including adjustment of the pulse pattern, operation temperature, and electroporation buffer, for fastest delivery of silver nanoparticles into living C666 cells (a human nasopharyngeal carcinoma cell line). The delivery efficiency was evaluated by the integrated intensity of whole cell SERS spectrum. Our work concluded that the silver nanoparticle delivery rate is best under the electroporation condition of using 4 consecutive $350 \mathrm{~V}(875 \mathrm{~V} / \mathrm{cm})$ rectangular electric pulses of 1, 10, 10 and $1 \mathrm{~ms}$ durations, respectively. Low temperature $\left(0-4{ }^{\circ} \mathrm{C}\right)$ is necessary for keeping cell viability during the electroporation process and it also improves the delivery efficiency of silver nanoparticles. The serum in the buffer has no obvious effect on the delivery efficiency.
\end{abstract}

Keywords: Surface-enhanced Raman scattering (SERS), electroporation, silver nanoparticle delivery, C666 cell

\section{Introduction}

With advantages in detection sensitivity, selectivity and specificity, surface-enhanced Raman scattering (SERS) spectroscopy is an analytical method with rapid expanding applications in chemical and biochemical analysis and detection. One such new application is intracellular SERS measurement, in which the metallic nanoparticles such as colloidal silver or gold are delivered into living cells to serve as the enhancing agent. The first feasibility data demonstrating the promising perspectives of SERS spectroscopy at a single-cell level was reported in 1991 [22]. At present, "endocytosis" is the dominant technique for delivering metal nanoparticles into living cells [5,16-18]. Using this method silver or gold nanoparticles have to be incubated with living cells at $37^{\circ} \mathrm{C}$ for more than several to twenties hours

\footnotetext{
*Yun Yu and Juqiang Lin are co-first authors; they contributed equally to the work.

${ }^{* *}$ Corresponding author: Prof. Rong Chen, Key Laboratory of OptoElectronic Science and Technology for Medicine, Ministry of Education and Fujian Provincial Key Laboratory for Photonics Technology, Fujian Normal University, Fuzhou 350007, China. Tel.: +86 5918348 9919; Fax: +86 5918346 5373; E-mail: chenr@ fjnu.edu.cn.
} 
prior to the SERS experiments. Besides this technique, biosynthesis of nanoparticles has also been tried in intracellular SERS study. Gold nanoparticles grown within the intracellular confines of living cells were introduced as potential SERS substrates in a few studies [1,27]. However, both the endocytosis technique and the biosynthesis technique are time-consuming. For many biomedical applications, such as cancer screening, keeping the cells alive for such a long time and delivering nanoparticles in such a slow fashion bring extra procedures and increase the cost.

To overcome the disadvantages of the two existing delivery techniques, we have recently developed an electroporation based method that can rapidly deliver silver nanoparticles into living cells within one minute and successfully carried out intracellular SERS measurements [20]. Electroporation involves the application of controlled electrical pulses to induce transient and reversible pores on the cell membrane. With these so-called "electropores", for a moment, the cell membrane becomes highly permeable to exogenous substances in the surrounding media $[9,10]$. Although electroporation is a powerful delivery technique for many molecules $[13,23]$, silver nanoparticles are not so easy to be delivered into living cells, because, on one hand, electroporation efficiency is influenced by many factors, such as voltage, pulse width, cell condition, operation temperature, serum concentration in electrical buffer $[10-12,15]$ and on the other hand, silver nanoparticles have shown bad biocompatibility with living cells [2,24]. Therefore, the primary objective of this study is to investigate the optimal electroporation parameters for obtaining the greatest delivery efficiency and at the same time ensuring cell viability. This optimization is important for practical applications of electroporation assisted intracellular SERS spectroscopy.

\section{Material and methods}

\subsection{Equipment}

The major equipment used in this study include a BTX-ECM 830 electroporator (Bio-Rad Laboratories Ltd, Shanghai, China), an electrode cuvette (electrodes $4 \mathrm{~mm}$ apart, Bio-Rad Laboratories Ltd) and a Renishaw micro-Raman spectrometer (InVia system).

\subsection{Preparation of silver nanoparticles}

Colloidal silver was prepared by the aqueous reduction of silver nitrate with hydroxylamine hydrochloride using a simple and fast method according to Leopold and Lendl [19]. First $4.5 \mathrm{ml}$ sodium hydroxide $(0.1 \mathrm{~mol} / \mathrm{l})$ was added to $5 \mathrm{ml}$ hydroxylamine hydrochloride $\left(6 \times 10^{-2} \mathrm{~mol} / \mathrm{l}\right)$ and then the mixtures were added rapidly to $90 \mathrm{ml}$ silver nitrate $\left(1.11 \times 10^{-3} \mathrm{~mol} / \mathrm{l}\right)$ with vigorous shaking. The silver colloids were rinsed by centrifugation at $10,000 \mathrm{rpm}$ for $10 \mathrm{~min}$ and then were kept in dark at room temperate. Figure 1 shows the electron micrograph and absorption spectrum of the silver colloid solution prepared. The average size of the silver nanoparticles is $\sim 40 \mathrm{~nm}$. The absorption maximum of the silver colloid was located at $419 \mathrm{~nm}$, very close to the value from literature of $416 \mathrm{~nm}$ [19].

\subsection{Cell culture}

Human nasopharyngeal carcinoma cells (C666 cell line) were obtained from the Fujian Medical University Union Hospital. C666 cells grow in the complete RPMI 1640 medium (supplemented with $100 \mathrm{IU} / \mathrm{ml}$ penicillin/streptomycin and $10 \%$ fetal calf serum, hereafter referred to as RPMI 1640) at 

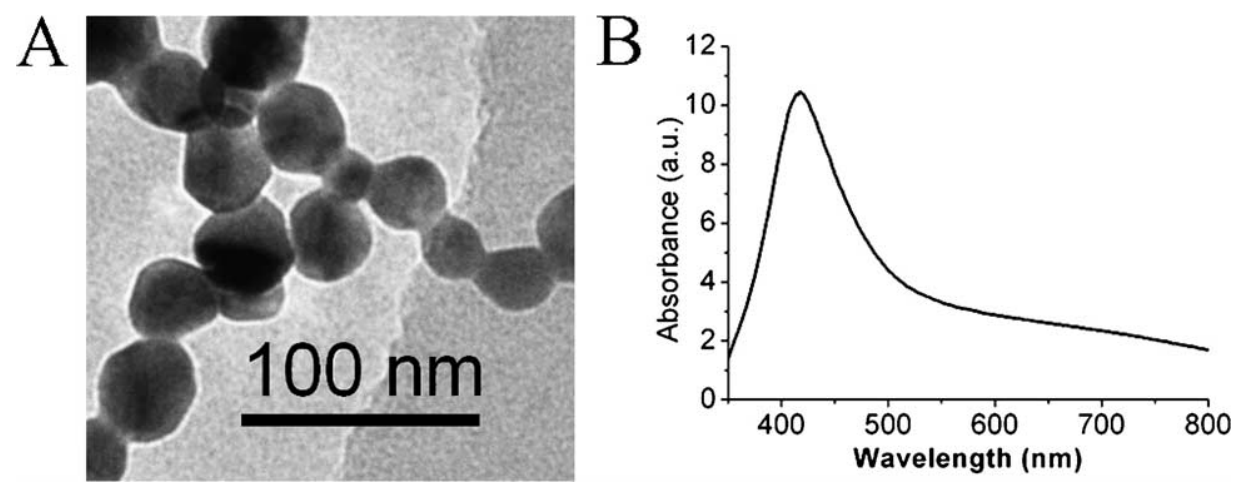

Fig. 1. (A) Electron micrograph of silver nanoparticles; (B) absorption spectra of silver nanoparticles in water. The average size of the silver nanoparticles is $\sim 40 \mathrm{~nm}$.

$37^{\circ} \mathrm{C}$ and $5 \% \mathrm{CO}_{2}$. Before electroporation, $\mathrm{C} 666$ cells were harvested from monolayer cultures by treatment with trypsin/EDTA solution, then the cells were washed three times by suspended in phosphate buffered saline (PBS) to remove any residual medium. After the cells were centrifuged, the cells were suspended in electroporation buffer with a density of $10^{6} \mathrm{cells} / \mathrm{ml}$, finally $800 \mu \mathrm{l}$ cell suspension and $200 \mu \mathrm{l}$ silver colloids were mixed thoroughly and added into an electrode cuvette. The silver colloid concentration used in this experiment was reduced by 10 times compared to our previous work [20] to avoid the excessive accumulation of silver nanoparticles surrounding the cells, which is hard to wash off.

\subsection{Stimulation parameters and operation conditions for cell electroporation}

Based on our previous study [20] a moderate voltage in the 350-375 V range is suitable for electroporation of cells. In this study we used a constant voltage of $350 \mathrm{~V}$ (corresponding to an field strength of $875 \mathrm{~V} / \mathrm{cm}$ ) for all the experiments. Other parameters including different series of electronic pulses, operation temperature and serum concentration in the electrical buffer were varied to identify optimum settings for electroporation delivery of silver nanoparticles into living C666 cells. Thus three optimization experiments were performed as outlined below.

\subsubsection{Influence of different pulse patterns}

The electroporation voltage was kept at $350 \mathrm{~V}$ (field strength of $875 \mathrm{~V} / \mathrm{cm}$ ), while five different pulse patterns were tested for best silver nanoparticle delivery efficiency: (1) $1 \mathrm{~ms}$ pulse width pulses for two times, (2) three consecutive pulses with pulse width of 1,10 and $1 \mathrm{~ms}$, respectively, (3) four consecutive pulses with pulse width of 1, 10, 10 and $1 \mathrm{~ms}$, respectively, (4) five consecutive pulses with pulse width of 1,10,10, 10 and $1 \mathrm{~ms}$, respectively, (5) five consecutive pulses with pulse width of 1, 10, 20, 10 and $1 \mathrm{~ms}$, respectively. For each experiment, the cell/silver nanoparticle mixture was first added into an electrode cuvette and incubated for $10 \mathrm{~min}$ at $4^{\circ} \mathrm{C}$ on ice and then transferred to an electroporation chamber to carry out the electroporation. The electrical buffer used was the complete RPMI 1640 medium. After each electroporation, the cuvette was incubated again for $10 \mathrm{~min}$ at $4{ }^{\circ} \mathrm{C}$ on ice. We also had a cell/silver nanoparticle mixture without electroporation as the control experiment. After the electroporation procedure, the C666 cells were washed twice with PBS to remove any residual buffer medium. After that, the cells were measured under the Renishaw micro-Raman spectrometer to obtain the SERS spectrum. In the control experiment, the C666 cells were also washed twice with PBS before the SERS spectral measurements. 


\subsubsection{Influence of operation temperature}

For the electroporation experiments with $350 \mathrm{~V}$ voltage and four consecutive pulses of pulse width 1 , $10,10,1 \mathrm{~ms}$ and in a complete RPMI 1640 medium buffer, two different operation temperatures were tested: cold $\left(0-4^{\circ} \mathrm{C}\right)$ and ambient room temperature $\left(20-25^{\circ} \mathrm{C}\right)$. The cold condition was obtained by placing the electrode cuvette in a freezer for 10 min before and after electroporation.

\subsubsection{Influence of serum in the buffer}

For the electroporation experiments with $350 \mathrm{~V}$ voltage and four consecutive pulses of pulse width 1 , $10,10,1 \mathrm{~ms}$ and under the cold operation temperature $\left(0-4{ }^{\circ} \mathrm{C}\right.$ on ice $)$, two different experiments were carried out with different fetal bovine serum concentrations for the electrical buffer: 0 and $10 \%$.

\subsection{SERS measurements}

A Renishaw Raman microscope (InVia system) with a $\sim 2 \lambda$ spatial resolution, a $20 \mathrm{~mW}, 785 \mathrm{~nm}$, semiconductor laser as excitation source, was used for the collection of SERS spectra. The microscope was operated under a $50 \times$ objective, which focused the laser beam onto a spot on the sample and the illumination pinhole was adjusted for the laser spot to cover the whole cell. The typical spectral accumulation time in our study was $10 \mathrm{~s}$. Raman spectra were scanned over a wavenumber range of $400-1800 \mathrm{~cm}^{-1}$ with respect to the excitation frequency.

\section{Results and discussion}

\subsection{The effects of electrical pulse pattern on the delivery efficiency of silver nanoparticles}

After electroporation, the cell morphology was observed by $50 \times$ microscopy. Figure 2 shows two example images. Under the same electric field strength $(875 \mathrm{~V} / \mathrm{cm})$, but different pulse pattern, the cells morphologies are different after electroporation. All the cells treated by pulse pattern 1 (1 ms pulse width pulses for two times) and pattern 2 (three consecutive pulses with pulse width of 1,10 and $1 \mathrm{~ms}$ ) and most of the cells treated by pulse pattern 3 (four consecutive pulses with pulse width of 1, 10, 10 and $1 \mathrm{~ms}$ ) have normal looking morphology (Fig. 2A). Many cells treated by pattern 4 (five consecutive pulses with pulse width of $1,10,10,10$ and $1 \mathrm{~ms}$ ) have normal looking morphology, but a significant fraction of the cells are broken. Most of the cells treated by pattern 5 (five consecutive pulses with pulse
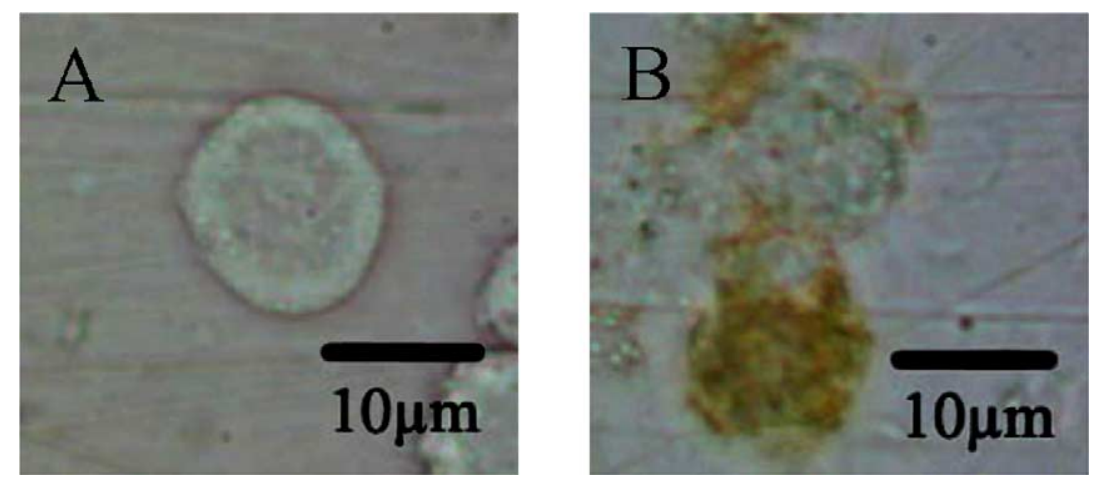

Fig. 2. Optical microscopic image of C666 cells after electroporation. (A) Normal looking cell; (B) broken cell. (Colors are visible in the online version of the article; http://dx.doi.org/10.3233/SPE-2010-0493.) 
width of 1, 10, 20, 10 and $1 \mathrm{~ms}$ ) are broken (Fig. 2B); some are fused together. The darker part in Fig. 2B shows the accumulation of silver nanoparticles, probably originated from the silver nanoparticle rushing-in after the cell membrane was irreversibly broken.

Figure 3A shows the SERS spectra of the control cell and cells at different electroporation treatment experiments. Spectrum "Ctrl" was measured from the control cell (without electroporation). The signal
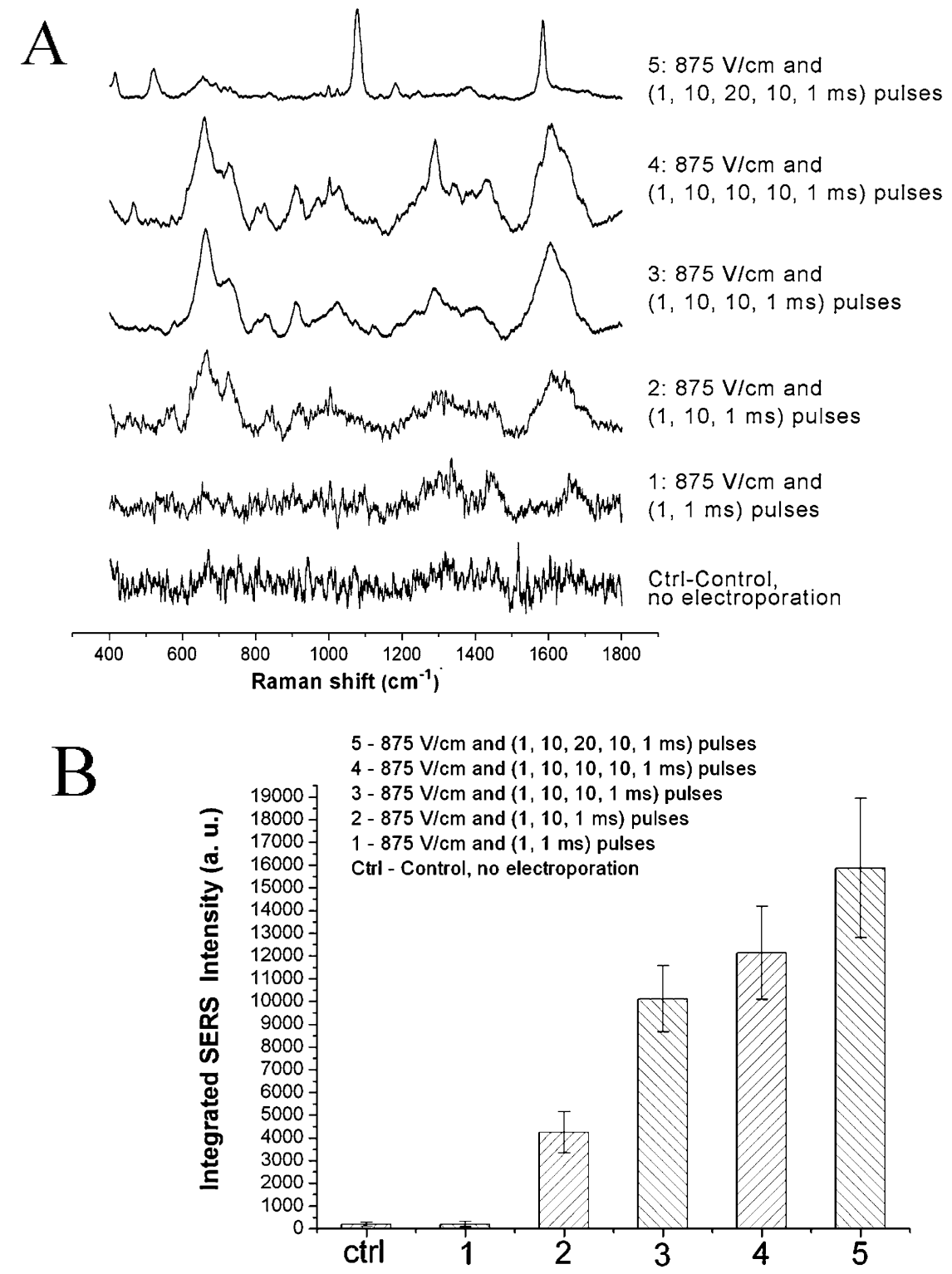

Fig. 3. (A) SERS spectra of C666 cells from control experiment (no electroporation) and five electroporation experiments of the same electric field strength $(875 \mathrm{~V} / \mathrm{cm})$, but different electrical pulse patterns: (1) $1 \mathrm{~ms}$ pulse width pulses for two times, (2) three consecutive pulses with pulse width of 1,10 and $1 \mathrm{~ms}$, respectively, (3) four consecutive pulses with pulse width of 1, 10, 10 and $1 \mathrm{~ms}$, respectively, (4) five consecutive pulses with pulse width of 1, 10, 10, 10 and $1 \mathrm{~ms}$, respectively, (5) five consecutive pulses with pulse width of 1,10,20, 10 and $1 \mathrm{~ms}$, respectively; (B) integrated SERS intensity (mean \pm SD) obtained from C666 cells in the control experiment and the five electroporation experiments. 
is very noisy; no reliable Raman peaks are seen. Spectrum 1 shows example SERS spectrum measured from individual living C666 cells treated by electric pulse pattern 1 (1 ms pulse width pulses for two times) and there are no reliable Raman peaks; spectrum 2 shows example SERS spectrum measured from individual living C666 cells treated by electric pulse pattern 2 (three consecutive pulses with pulse width of 1,10 and $1 \mathrm{~ms}$ ); Raman peaks are visible, but not good enough $\mathrm{S} / \mathrm{N}$. Spectrum 3 shows example SERS spectrum measured from individual living C666 cells treated by electric pulse pattern 3 (four consecutive pulses with pulse width of 1,10,10 and $1 \mathrm{~ms}$ ); good quality SERS spectra were obtained, containing a wealth of intracellular surface-enhanced Raman signals. This is the optimal electroporation parameter for efficient silver nanopartical delivery into living C666 cells. Spectrum 4 shows example SERS spectrum measured from individual living C666 cells (normal looking morphology) treated by electric pulse pattern 4 (five consecutive pulses with pulse width of 1,10,10,10 and $1 \mathrm{~ms}$ ); the quality of the spectrum is as good as spectrum 3. However, a significant portion of the cells treated by pattern 4 are broken (spectra date of the broken cells not shown), making this pulse pattern unusable. With the irreversible electroporation generated by pulse pattern 5 (five consecutive pulses with pulse width of 1 , $10,20,10$ and $1 \mathrm{~ms}$ ), the cells were broken; the corresponding example SERS spectra are shown as spectrum 5, very different from spectra 3 and 4 from the living cells. Moreover, SERS spectra from the broken cells are different from each other (data not shown).

The delivery efficiency is evaluated quantitatively by the integrated SERS intensity. For each electroporation experiment, SERS measurements were performed on fifteen cells and two spectra were acquired from each cell by repeated measurements. Therefore, in total thirty SERS spectra were obtained during each experiment. While for every spectrum, we calculated the total integrated area under the curve from 400 to $1800 \mathrm{~cm}^{-1}$. Then the integrated intensity was divided by the area of the cell to generate a standardized "integrated SERS intensity", representing the total amount of silver nanoparticles delivered into the cell. With these data processing applied to the five different electroporation experiments and the control experiment, we obtained a comparison bar graph as shown in Fig. 3B. For the control experiment and the electroporation experiment with electric pulse pattern 1 (1 ms pulse width pulses for two times), the integrated SERS intensities are minimal, indicating that very little silver nanoparticles were delivered into the cells. Compared with this, the cells treated by the electric pulse pattern 2 (three consecutive pulses with pulse width of 1, 10 and $1 \mathrm{~ms}$ ) achieved considerable integrated SERS intensity. This suggested that considerable amount of silver nanoparticles were delivered into living C666 cells. The cells treated by the electric pulse pattern 3 (four consecutive pulses with pulse width of 1, 10, 10 and $1 \mathrm{~ms}$ ) showed strong integrated SERS intensity. This result demonstrated that $875 \mathrm{~V} / \mathrm{cm}$ electric field strength and four pulses of 1, 10,10,1 ms width led to a high delivery efficiency of silver nanoparticles into living C666 cells. The integrated SERS intensity of cells treated by the electric pulse pattern 4 (five consecutive pulses with pulse width of 1,10,10,10 and $1 \mathrm{~ms}$ ) is even higher, but a significant portion of cells were broken. The integrated SERS intensity of broken cells from the excessive electroporation $(875 \mathrm{~V} / \mathrm{cm}$ and five pulses of 1,10,20,10,1 ms width) is the highest, probably caused by the aggregation of excessive silver nanoparticles accumulated after the cell membrane was irreversibly broken. Recent investigations have shown that the aggregated silver nanoparticle clusters generate SERS hot spots where the Raman signals are enhanced a few orders of magnitude $[8,14,26]$. However, this is not useful because the cells are dead and corresponding Raman signals are very different from the cells that are still alive after the electroporation treatment by the electric pulse pattern 3 (four consecutive pulses with pulse width of 1 , 10,10 and $1 \mathrm{~ms}$ ). In the electric pulse pattern 3 treatment, the silver nanoparticles are rapidly delivered into the cells and the cell membrane also recovered its integrity and functions normally, maintained the viability of the cells. 


\subsection{The effects of temperature on the delivery efficiency of silver nanoparticles}

The temperature at the electroporation process might play a role in the efficiency of delivery and survival of cells because application of an electric field causes cell heating, especially at high field strengths and long pulse time $[3,6,7]$, The electroporation procedure was performed at $\left(0-4^{\circ} \mathrm{C}\right)$ or at room temperature $\left(20-25^{\circ} \mathrm{C}\right)$ to determine the optimal electroporation temperature with the same electrical parameters $(875 \mathrm{~V} / \mathrm{cm}$ field strength and four pulses of $1,10,10,1 \mathrm{~ms}$ pulse width).

Our study shows that the survival rate of C666 cells with electroporation operated in room temperature was inferior to when the cells were electroporated at the low temperature $\left(0-4^{\circ} \mathrm{C}\right)$. Under the room temperature operation, many cells were broken probably because of their thermal injury during the electroporation. This result is consistent with other reports of thermal damage and thermal ablation during electroporation $[7,21,25]$. Therefore, keeping the cells at low temperature $\left(0-4^{\circ} \mathrm{C}\right)$ before and following electroporation can reduce cell heating, thereby increases cell survival rate.

We also used the integrated SERS intensity to compare the efficiency of silver nanoparticles delivery in these two experiments. Figure 4A shows that, compared with low operation temperature, the integrated SERS intensity of cell electroporation in room temperature decreased dramatically. For the operation temperature of $0-4{ }^{\circ} \mathrm{C}$, the mean and standard deviation of integrated SERS intensity were $10.2 \times 10^{3} \pm$ $1.3 \times 10^{3}(12.7 \%)$, while for the room temperature operation, it is $6.87 \times 10^{3} \pm 0.93 \times 10^{3}(13.5 \%)$. The differences are significant $(p=0.000<0.05$, Student's $t$-test). Therefore, it is importance to maintain the cells at low temperature condition for the electroporation operation for optimal silver nanoparticle delivery efficiency and cell viability. One explanation for this result is that keeping the cells at low temperature allows the electroporation-induced pores on the membrane to remain open longer $[4,9]$ and more silver nanoparticles in the medium will get into the cell.

\subsection{The effects of serum on the delivery efficiency of silver nanoparticles}

The choice of the electroporation buffer is critical for optimizing electroporation because the electrical resistance of the medium is a major factor in generating the electric shock. It is well accepted that cell

A

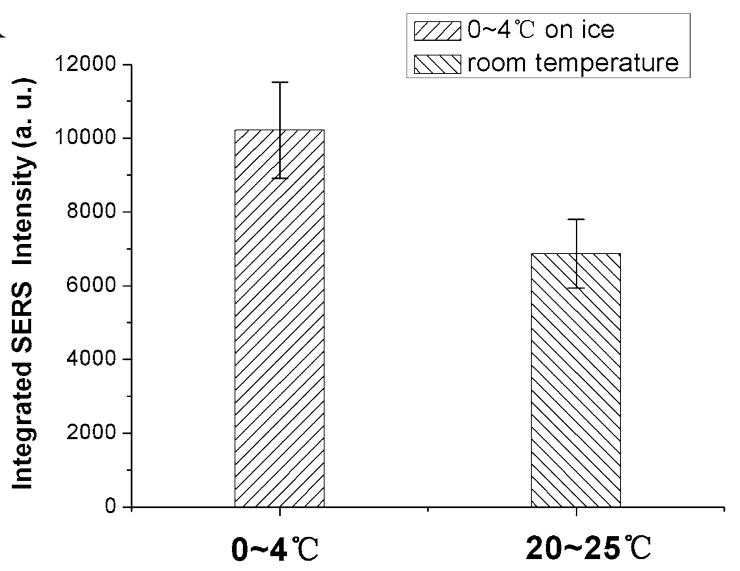

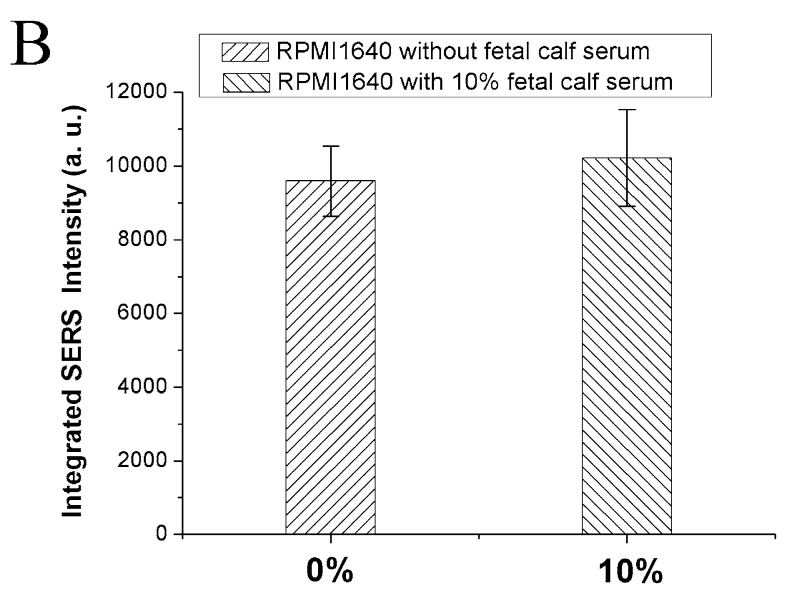

Fig. 4. Comparison of integrated SERS intensity (mean \pm SD) obtained from living C666 cells under different electroporation operation temperature (A) and at different serum concentrations of the buffer medium (B). 
culture medium without serum is recommended as the first choice for electroporation buffer [10]. However, the optimal medium for any specific cell line must be determined empirically and our experiment results for C666 cells are against this recommendation.

As shown in Fig. 4B, the mean and standard deviation of integrated SERS intensity for the serumfree $(0 \%)$ buffer and the serum-containing $(10 \%)$ buffer were $9.59 \times 10^{3} \pm 0.95 \times 10^{3}(9.8 \%)$ and $10.2 \times 10^{3} \pm 1.3 \times 10^{3}(12.7 \%)$, respectively. The differences are not significant $(p=0.142>0.05$, Student's $t$-test). This suggests that the serum in the electroporation buffer has no obvious effect on the efficiency of delivering silver nanoparticles into living C666 cells. It is not necessary to eliminate the serum, the complete RPMI 1640 medium can be directly used as the electroporation buffer. This simplifies the preparations for the electroporation and the related cell damage is minimized.

\section{Conclusion}

In conclusion, we optimized the electroporation parameters for delivering silver nanoparticles into living C666 cells for intracellular SERS spectroscopy. The optimum delivery is achieved under the electroporation condition of using 4 consecutive $350 \mathrm{~V}(875 \mathrm{~V} / \mathrm{cm})$ rectangular electric pulses of $1,10,10$ and $1 \mathrm{~ms}$ durations, respectively. Low temperature $\left(0-4^{\circ} \mathrm{C}\right)$ is necessary for maintaining cell viability during the electroporation process and it also improves the delivery efficiency of silver nanoparticles. The serum in the buffer has no obvious effect on the delivery efficiency. With the optimized electroporation procedure, intracellular SERS analysis can be performed within minutes, offering great promises for biomedical applications such as high-throughput cancer cell screening.

\section{Acknowledgements}

This work was supported by the National Natural Science Foundation of China (Nos 60778046 and 60910106016), the Science and Technology Project of Fujian Province (Nos 2008J0016 and 2009J01276), the Project of Science Foundation of Ministry of Health and United Fujian Provincial Health and Education Project for Tackling the Key Research (No. WKJ2008-2-046) and the Canadian Institutes of Health Research International Scientific Exchange Program.

\section{References}

[1] A. Anshup, J.S. Venkataraman, C. Subramaniam, R.R. Kumar, S. Priya, T.R.S. Kumar, R.V. Omkumar, A. John and T. Pradeep, Growth of gold nanoparticles in human cells, Langmuir 21 (2005), 11562-11567.

[2] O. Akhavan and E. Ghaderi, Enhancement of antibacterial properties of Ag nanorods by electric field, Science and Technology of Advanced Materials 10 (2009), 015003.

[3] P. Canatella, J. Karr, J. Petros and M. Prausnitz, Quantitative study of electroporation-mediated molecular uptake and cell viability, Biophysical Journal 80 (2001), 755-764.

[4] C. Chen, S. Smye, M. Robinson and J. Evans, Membrane electroporation theories: a review, Medical and Biological Engineering and Computing 44 (2006), 5-14.

[5] I. Chourpa, F.H. Lei, P. Dubois, M. Manfait and G.D. Sockalingum, Intracellular applications of analytical SERS spectroscopy and multispectral imaging, Chemical Society Reviews 37 (2008), 993-1000.

[6] R. Davalos and B. Rubinsky, Temperature considerations during irreversible electroporation, International Journal of Heat and Mass Transfer 51 (2008), 5617-5622.

[7] R. Davalos, B. Rubinsky and L. Mir, Theoretical analysis of the thermal effects during in vivo tissue electroporation, Bioelectrochemistry 61 (2003), 99-107. 
[8] S. Feng, J. Lin, M. Cheng, Y.Z. Li, G. Chen, Z. Huang, Y. Yu, R. Chen and H. Zeng, Gold nanoparticle based surfaceenhanced Raman scattering spectroscopy of cancerous and normal nasopharyngeal tissues under near-infrared laser excitation, Applied Spectroscopy 63 (2009), 1089-1094.

[9] J. Gehl, Electroporation: theory and methods, perspectives for drug delivery, gene therapy and research, Acta Physiologica Scandinavica 177 (2003), 437-447.

[10] W.C. Heiser, Optimizing electroporation conditions for the transformation of mammalian cells, Methods in Molecular Biology 130 (2000), 117-134.

[11] S.W. Hui, Effects of pulse length and strength on electroporation efficiency, in: Animal Cell Electroporation and Electrofusion Protocols, J.A. Nickoloff, ed., Humana Press, Totowa, NJ, USA, 1995, pp. 29-40.

[12] S.W. Hui, Overview of drug delivery and alternative methods to electroporation, in: Electroporation Protocols, S. Li, ed., Humana Press, Totowa, NJ, USA, 2008, pp. 91-107.

[13] M. Jaroszeski, V. Dang, C. Pottinger, J. Hickey, R. Gilbert and R. Heller, Toxicity of anticancer agents mediated by electroporation in vitro, Anti-Cancer Drugs 11 (2000), 201.

[14] J. Jiang, K. Bosnick, M. Maillard and L. Brus, Single molecule Raman spectroscopy at the junctions of large Ag nanocrystals, The Journal of Physical Chemistry B 107 (2003), 9964-9972.

[15] M. Kandušer and D. Miklavčič, Electroporation in biological cell and tissue: an overview, in: Electrotechnologies for Extraction from Food Plants and Biomaterials, Springer, New York, 2009, pp. 1-37.

[16] K. Kneipp, A.S. Haka, H. Kneipp, K. Badizadegan, N. Yoshizawa, C. Boone, K.E. Shafer-Peltier, J.T. Motz, R.R. Dasari and M.S. Feld, Surface-enhanced Raman spectroscopy in single living cells using gold nanoparticles, Applied Spectroscopy 56 (2002), 150-154.

[17] J. Kneipp, H. Kneipp, W.L. Rice and K. Kneipp, Optical probes for biological applications based on surface-enhanced Raman scattering from indocyanine green on gold nanoparticles, Analytical Chemistry 77 (2005), 2381-2385.

[18] S. Lee, S. Kim, J. Choo, S. Shin, Y. Lee, H. Choi, S. Ha, K. Kang and C. Oh, Biological imaging of HEK293 cells expressing PLC $\gamma 1$ using surface-enhanced Raman microscopy, Analytical Chemistry 79 (2007), 916-922.

[19] N. Leopold and B. Lendl, A new method for fast preparation of highly surface-enhanced Raman scattering (SERS) active silver colloids at room temperature by reduction of silver nitrate with hydroxylamine hydrochloride, The Journal of Physical Chemistry B 107 (2003), 5723-5727.

[20] J. Lin, R. Chen, S. Feng, Y. Li, Z. Huang, S. Xie, Y. Yu, M. Cheng and H. Zeng, Rapid delivery of silver nanoparticles into living cells by electroporation for surface-enhanced Raman spectroscopy, Biosensors and Bioelectronics 25 (2009), 388-394.

[21] L. Miller, J. Leor and B. Rubinsky, Cancer cells ablation with irreversible electroporation, Technology in Cancer Research and Treatment 4 (2005), 699-705.

[22] I.R. Nabiev, H. Morjani and M. Manfait, Selective analysis of antitumor drug interaction with living cancer cells as probed by surface-enhanced Raman spectroscopy, European Biophysics Journal 19 (1991), 311-316.

[23] T. Niidome and L. Huang, Gene therapy progress and prospects: nonviral vectors, Gene Therapy 9 (2002), 1647-1652.

[24] A. Panáek, L. Kvítek, R. Prucek, M. Kolář, R. Veeřová, N. Pizúrová, V.K. Sharma, T.J. Nevěná and R. Zbořil, Silver colloid nanoparticles: synthesis, characterization, and their antibacterial activity, The Journal of Physical Chemistry $B$ 110 (2006), 16248-16253.

[25] B. Rubinsky, Irreversible electroporation in medicine, Technology in Cancer Research and Treatment 6 (2007), 255.

[26] A. Sengupta, M. Laucks and E. Davis, Surface-enhanced Raman spectroscopy of bacteria and pollen, Applied Spectroscopy 59 (2005), 1016-1023.

[27] A. Shamsaie, M. Jonczyk, J. Sturgis, J.P. Robinson and J. Irudayaraj, Intracellularly grown gold nanoparticles as potential surface-enhanced Raman scattering probes, Journal of Biomedical Optics 12 (2007), 020502. 


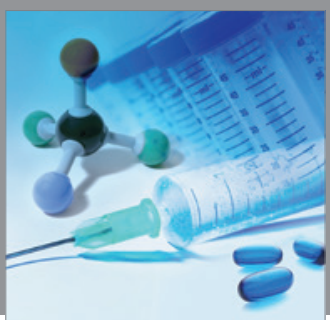

International Journal of

Medicinal Chemistry

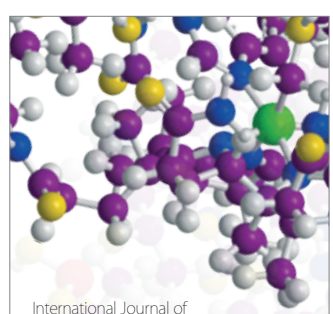

Carbohydrate Chemistry

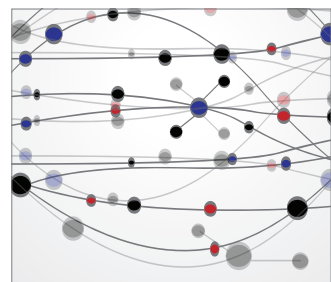

The Scientific World Journal
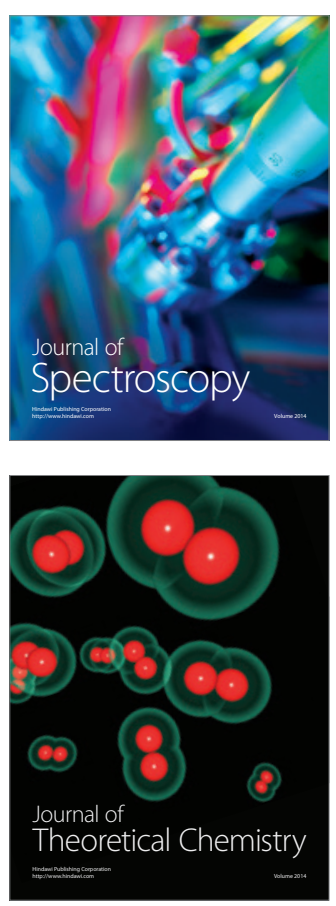
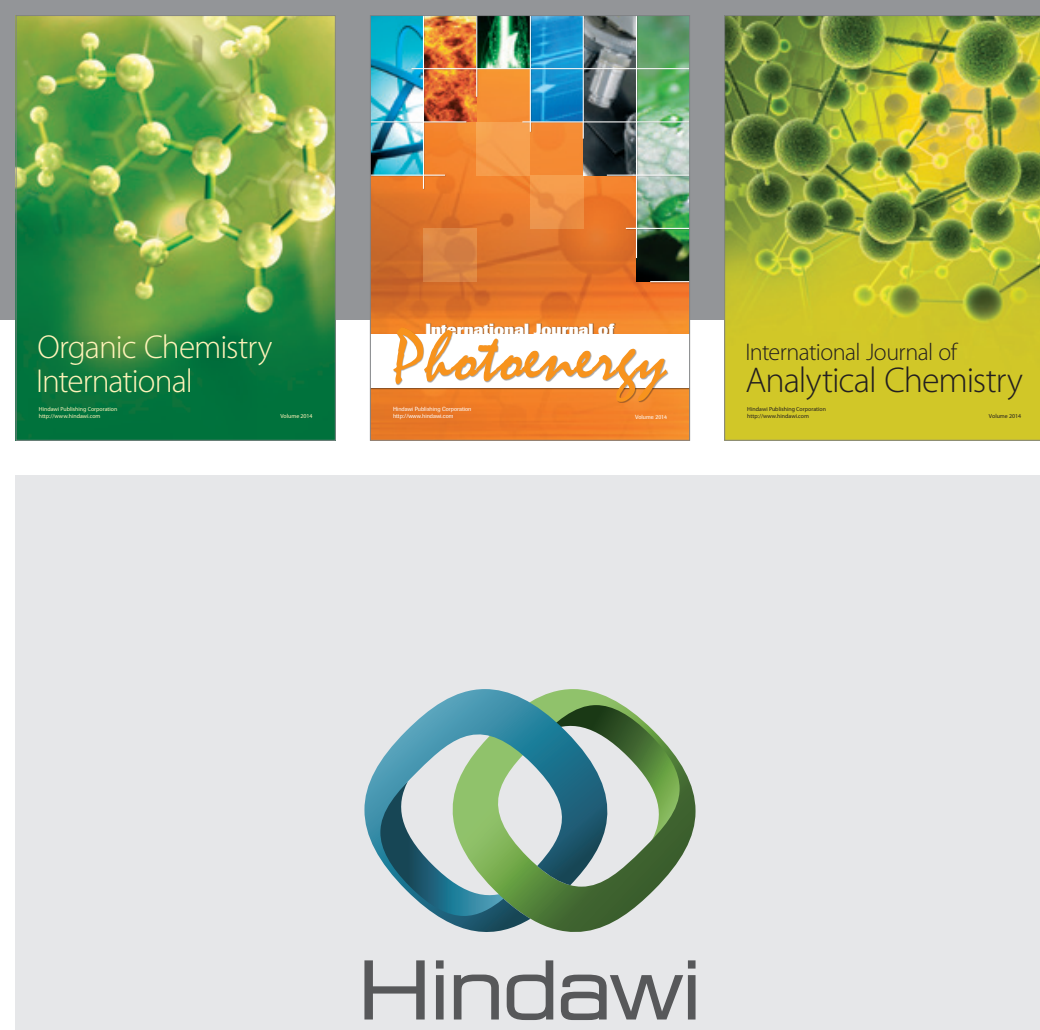

Submit your manuscripts at

http://www.hindawi.com
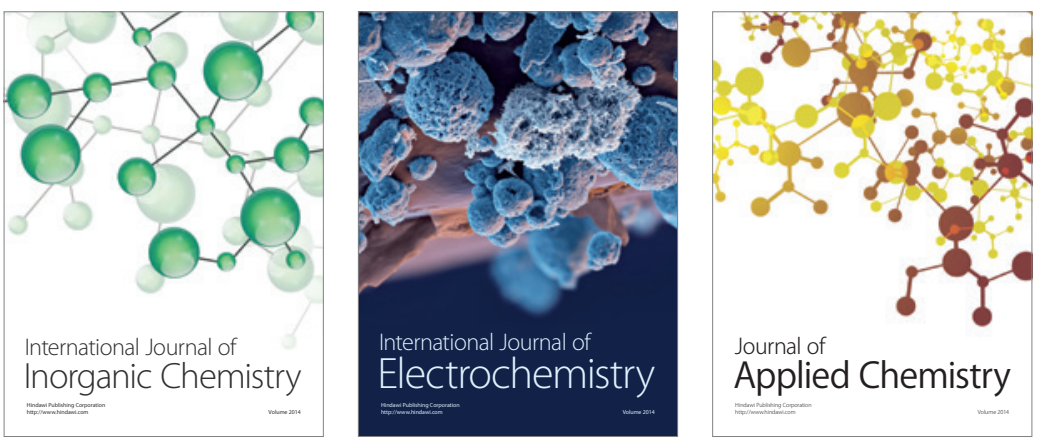

Journal of

Applied Chemistry
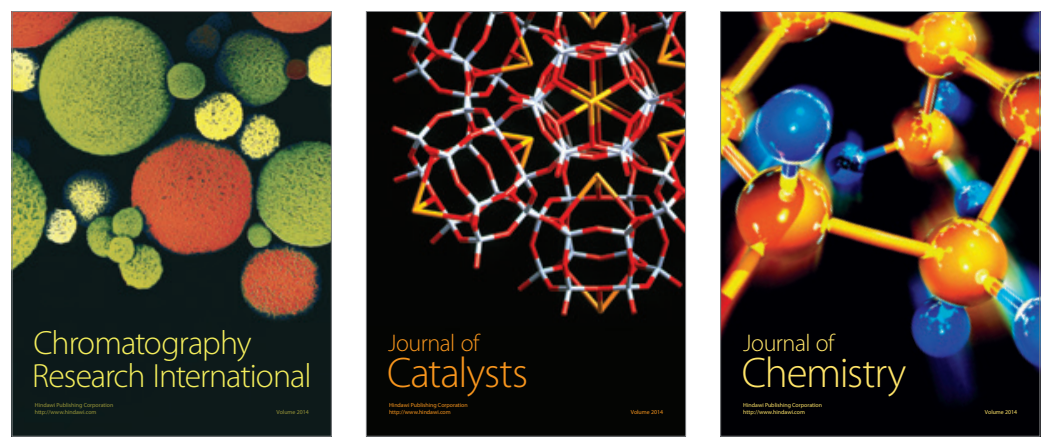
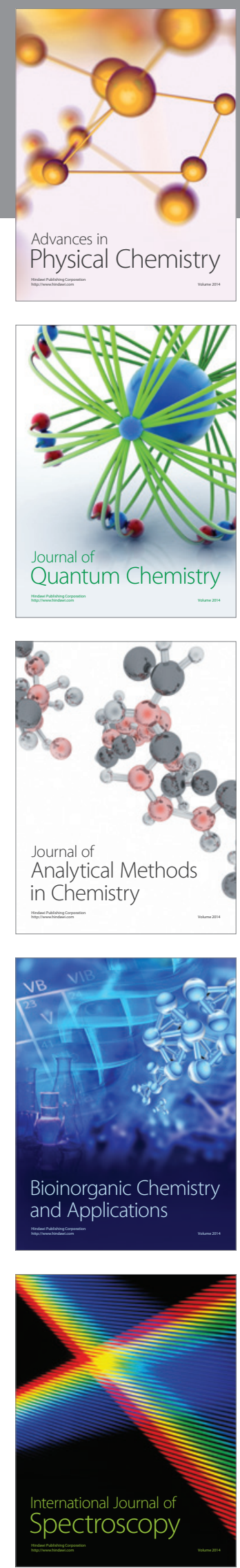